\title{
Introduction to Special Issue: Addressing Aggression and Violence in Diverse School Settings
}

\author{
Meagan O'Malley $^{1} \cdot$ Stephen E. Brock ${ }^{1}$ \\ Published online: 1 September 2020 \\ (C) California Association of School Psychologists 2020
}

Little time passes without a new report of violence occurring in or near US schools. It is difficult to turn on the television or check social media without seeing violent images of youth being physically and verbally assaulted by school-based law enforcement; communities living in fear of, or coping with, mass school shootings; and, in urban areas, a relentless epidemic of gun violence causing deaths and injuries to hundreds of young people each year. Among a growing set of Americans, awareness about the prevalence of structural violence and discriminatory violence in schools, and society, is growing. For all these reasons, many young people, educators, and community members are disturbed and justifiably outraged.

Trends in national data suggest good cause for concern, as well as some glimmers of hope, as indicators of school-related violence suggest mixed patterns over the past 10-year period. First, little progress has been made in reducing school avoidance due to safety concerns, being threatened or injured with a weapon at school, and being bullied at school or electronically in the past year (Kann et al. 2018). Discriminatory bullying (i.e., bullying because of race, gender, sexual orientation, or religion) has not historically been measured on the national Youth Risk Behavioral Surveillance System (YRBSS; Kann et al. 2018), but state-level data from California suggest a positive trend from 2011 to 2019 , with youth reporting decreases in bullying and harassment due to race, religion, sexual orientation, and disability (Austin et al. 2020). Critically, violence toward self, including suicidal and non-suicidal selfinjury, has risen over the most recent decade (Burstein et al. 2019; Kann et al. 2018). Students report increases in persistent feelings of sadness or hopelessness (Kann et al. 2018), and notably, suicide accounted for $19.2 \%$ of all deaths of young

Meagan O’Malley

meagan.omalley@csus.edu

1 California State University, Sacramento, CA, USA people ages 10-24 in the USA in 2017, making it the second leading cause of death for this age group (Heron 2019).

Youth exposed to violence, including those who are victims, offenders, and/or witnesses, often experience personal and academic challenges as a result. Exposure to violence has been associated with psychosocial distress, delinquency, and impaired learning and functioning at school (Polanin et al. 2020). This special issue of Contemporary School Psychology addresses supports for preventing school-related violence in all its forms and for reducing the deleterious effects of exposure to school-related violence. The eight included works describe recent developments in state-level policy making related to school safety, restorative and culturally relevant approaches to violence prevention and intervention, technological advances for preventing violent acts, and characteristics of research-practice partnerships for expanding the adoption of evidence-based school violence prevention and intervention approaches.

\section{Contributions to the Special Issue}

School safety has been, and sometimes still is, reductively construed as a disruption-free environment, the logic being that if physical disruptions are eliminated from campus, then the campus is safe. However, psychological safety transcends physical safety, and the quality of students' relationships with peers and educators on school campus is critical for reducing the prevalence and impact of physical (Castillo-Eito et al. 2020), interpersonal (Kljakovic and Hunt 2016), and self-directed violence (Marraccini and Brier 2017). Contributing to this body of evidence, Hatzichristou et al. (2020, this issue) examine the mediating effect of school-based interpersonal supports on the relationship between economic instability and subjective wellbeing among junior high school students in Athens, Greece. They found that among students experiencing economic instability, subjective well-being improved when students reported 
positive peer relations, effective school-level bullying prevention efforts, and school-level respect for diversity.

Limiting school safety efforts to physical safety measures, and conceptualizing safety simply as a disruption-free environment, has led many state and local education agencies to adopt punitive and exclusionary discipline practices, such as zero tolerance policies, which have been widely criticized as reactionary and crudely applied (Carter et al. 2017). While court rulings against school districts' disproportional use of exclusionary discipline are evident as early as the 1970s (e.g., Hawkins V. Coleman, 1974; Goss V. Lopez, 1975), minoritized youth, including young people of color and young people with disabilities, continue to bear the greatest burden of these policies (Triplett et al. 2014). Rooted in this punitive tradition, these policies have contributed to the alienation of youth from the personal and academic support structures available in schools (Carter et al. 2017) and to the criminalization of youth (Mallett 2016). Borunda and Martinez (2020, this issue) push back against a traditionally ahistorical approach to explaining disparities in school experiences among minoritized youth, Xicanx youth in particular, arguing that structural violence caused by systemic nativism and white supremacy is their root cause.

As growing swaths of the public have decried ill-conceived school violence prevention policies, some pioneering states have begun to draft alternative policy recommendations. The Education Commission of the States (ECS) recently published a 50-state comparison of school safety policies (Macdonald and Perez 2019). Mann and Brock (2020, this issue) draw upon the ECS report to argue for more deliberate, proactive, and empirically supported violence prevention practices, including those regulating police presence on school campuses, a politically polarizing topic of growing public interest.

The development and dissemination of innovative strategies for maintaining violence-free, developmentally supportive schools, have occurred alongside improved policy guidance. From 2014 to 2017 the US National Institute of Justice (NIJ 2018) allocated nearly 250 million dollars to support innovations in school safety programs and practices. Projects examining the effectiveness of restorative justice, an approach that gained popularity after some early-adopter school districts (e.g., Denver Public Schools, Oakland Unified School district) reported reductions in disproportional discipline, received substantial NIJ funding during this period. Reviewing outcomes from those studies and others, Darling-Hammond et al. (2020, this issue) describe the evidence for restorative justice practices in schools, including evidence for reductions in physical violence and behavioral disruptions on campus, and reductions in racial disparities in exclusionary discipline. While agreeing that restorative practices may be superior to an exclusionary discipline approach, Romero et al. (2020, this issue) caution that absent efforts to address implicit bias, racially based discipline gaps will persist. Romero et al. (2020) go on to describe the research foundation for strategies intended to directly address implicit bias in school discipline decision making.

Of course, having access to programs and practices supported by rigorous evidence of effectiveness is a foundational step, but community uptake of evidence-based approaches demands capacity-building among state and local policy makers, effective communication with diverse school stakeholders in local communities, and careful implementation practices. These opportunities require a specialized set of skills and strategies for navigating the real world of schools. Three articles in this special issue address challenges and opportunities involved in adopting and installing evidence-based violence prevention and intervention approaches in schools serving diverse stakeholders in varied geographical regions of the USA. First, Byars et al. (2020, this issue) describe a research-practice partnership aimed at preventing youth suicide through effective monitoring of social media and technology use in a suburban school district. Byars et al. (2020) chronicle the process of building support among district leadership, educators, and families; selecting Go Guardian, an internet-monitoring application; and developing and installing a crisis response plan for addressing technology alerts. Notable is the district's steady decline in office discipline referrals, in-school suspensions, and out-of-school suspensions over the partnership period. Working in Atlanta Public Schools, one of the largest urban school districts in the USA, Terrell et al. (2020, this issue) describe another federal grant-funded research-practice partnership aimed at growing educators' skills for making data-based decisions in their school violence prevention and intervention planning. Lastly, drawing on innovations from implementation science, Woitaszewski et al. (2020, this issue) describe opportunities to expand the reach and effectiveness of the National Association of School Psychologists (NASP) PREPaRE school safety and crisis management curriculum (Brock et al. 2016).

\section{Future Directions}

This special issue contains eight thoughtful pieces of scholarship that collectively challenge us to consider the root causes of violence perpetrated in and by schools; that offer innovations in policies, practices, and programs for school-related violence prevention and intervention; and that illuminate new directions for reducing exposure to, and limiting the impact of, violence among young people in schools. At the time this article is going to press, we are anticipating the imminent release of results from the 2019 national YRBSS, from which we will be able to draw new inferences about trends in schoolrelated violence. Informed by these results, we anticipate future scholarship will address several critical areas, including the rise in self-directed violence among youth, the need for culturally relevant supports for historically minoritized youth, and supports for phases wherein a young person is shifting 
across developmental stages (e.g., transition-aged youth who are making a developmental shift from school to community settings) or between youth-serving sectors (e.g., re-entry from juvenile justice to education setting).

Ultimately, we hope that articles in this special issue find a motivated audience. We encourage readers to contact contributors to the special issue for more information about opportunities to install school-based supports that reduce the impact of violence on the well-being of young people in our communities.

Acknowledgments We wish to thank Michael Hass, Editor-in-Chief, for supporting the development of this special issue, as well as the many colleagues who thoughtfully reviewed submitted manuscripts.

\section{References}

Austin, G., Hanson, T., Zhang, G. \& Zheng, C. (2020). California healthy kids survey: results of the Seventeenth Biennial Statewide Student Survey, Grades 7, 9, and 11. https://data.calschls.org/resources/ Biennial_State_1517.pdf

Burstein, B., Agostino, H., \& Greenfield, B. (2019). Suicidal attempts and ideation among children and adolescents in US emergency departments, 2007-2015. JAMA Pediatrics, 173(6), 598-600. https:// doi.org/10.1001/jamapediatrics.2019.0464.

Borunda, R. \& Martinez, L. (2020). Strategies for defusing contemporary weapons in the ongoing war against Xicanx children and youth. Contemporary School Psychology, Advance online publication. https://doi.org/10.1007/s40688-020-00312-x

Brock, S. E., Nickerson, A. B., Louvar Reeves, M. A., Conolly, C. N., Jimerson, S. R., Pesce, R. C., \& Lazzaro, B. R. (2016). School crisis prevention and intervention: the PREPaRE model (2nd ed.) National Association of School Psychologists.

Byars, J., Graybill, E., Wellons, Q., \& Harper, L. (2020). Monitoring social media and technology use to prevent youth suicide and school violence. Contemporary School Psychology. Advance online publication. https://doi.org/10.1007/s40688-020-00277-x.

Carter, P., Skiba, R., Arredondo, M., \& Pollock, M. (2017). You can’t fix what you don't look at: Acknowledging race in addressing racial discipline disparities. Urban Education, 52(2), 207-235. https://doi. org/10.1177/0042085916660350.

Castillo-Eito, L., Armitage, C., Norman, P., Day, M., Dogru, O., \& Rowe, R. (2020). How can adolescent aggression be reduced? A multi-level meta-analysis. Clinical Psychology Review, 78, 101853. https://doi.org/10.1016/j.cpr.2020.101853.

Darling-Hammond, S., Fronius, T.A., Sutherland, H., Guckenburg, S., Petrosino, A., \& Hurley, N. (2020). Effectiveness of restorative justice in US K-12 schools: a review of quantitative research. Contemporary School Psychology. Advance online publication. https://doi.org/10.1007/s40688-020-00290-0

Hatzichristou, C., Lianos, P., Lampropoulou, A., \& Stasinou, V. (2020). Individual and systemic factors related to safety and relationships in schools as moderators of adolescents' subjective well-being during unsettling times. Contemporary School Psychology. Advance online publication. https://doi.org/10.1007/s40688-020-00298-6

Heron, M. (2019). Deaths: leading causes for 2017. National Vital Statistics Report, 68(6). https://stacks.cdc.gov/view/cdc/79488.

Kann, L., McManus, T., Harris, W. A., Shanklin, S. L., Katherine H. Flint, K. H., Queen, B., Lowry, R., Chyen, D., Whittle, L., Thornton, J., Lim, C., Bradford, D., Yamakawa, Y., Leon, M., Brener, N., \& Ethier, K. A. (2018). Youth risk behavior
surveillance-United States, 2017. MMWR, 67(8), 1-114. https:// www.cdc.gov/healthyyouth/data/yrbs/pdf/2017/ss6708.pdf

Kljakovic, M., \& Hunt, C. (2016). A meta-analysis of predictors of bullying and victimisation in adolescence. Journal of Adolescence, 49, 134-145. https://doi.org/10.1016/j.adolescence.2016.03.002.

Macdonald, H. \& Perez, Z. (2019). 50-state comparison: K-12 school safety. Education Commission of the States. https://www.ecs.org/ 50-state-comparison-k-12-school-safety/

Mallett, C. A. (2016). The school-to-prison pipeline: a critical review of the punitive paradigm shift. Child \& Adolescent Social Work Journal, 33(1), 15-24. https://doi.org/10.1007/s10560-015-0397-1.

Mann, A., \& Brock, S. E. (2020). Analysis of safety policy making: implications for school psychologists. Contemporary School Psychology. Advance online publication. https://doi.org/10.1007/ s40688-020-00297-7.

Marraccini, M. E., \& Brier, Z. M. F. (2017). School connectedness and suicidal thoughts and behaviors: a systematic meta-analysis. School Psychology Quarterly, 32(1), 5-21. https://doi.org/10.1037/ spq0000192.

National Institute of Justice (2018). NIJ's Comprehensive School Safety Initiative. https://nij.ojp.gov/topics/articles/nijs-comprehensiveschool-safety-initiative

Polanin, J., Espelage, D., \& Grotpeter, J. (2020). The consequences of school violence: a systematic review and meta-analysis. https:// www.ncjrs.gov/pdffiles1/nij/grants/254672.pdf

Romero, L., Scahill, V., \& Charles, S. (2020). Restorative approaches to discipline and implicit bias: looking for ways forward. Contemporary School Psychology. Advance online publication.

Terrell et al. (2020). Conceptualizing and measuring safe and supportive schools. Contemporary School Psychology. https://doi.org/10.1007/ s40688-020-00309-6

Triplett, N. P., Allen, A., \& Lewis, C. W. (2014). Zero tolerance, school shootings, and the post-Brown quest for equity in discipline policy: an examination of how urban minorities are punished for White suburban violence. Journal of Negro Education, 83(3), 352-370. https://doi.org/10.7709/jnegroeducation.83.3.0352.

Woitaszewski, S., Savage, T., \& Zaslofsky, A. (2020). From neutral to high gear: critical implementation drivers for PREPaRE in Practice. Contemporary School Psychology. Advance online publication.

Publisher's Note Springer Nature remains neutral with regard to jurisdictional claims in published maps and institutional affiliations.

Dr. Meagan O'Malley Associate Professor in the School Psychology graduate program at Sacramento State University, specializes in schoolbased mental health promotion and violence prevention among children, youth, and young adults. Dr. O'Malley's scholarship on psychological wellbeing and school climate perceptions, particularly as they vary across youth with diverse life experiences, has been published in several peerreviewed journals and edited volumes. Dr. O'Malley is the current Program Chair for the School Culture and Climate special interest group (SIG) of the American Educational Research Association (AERA). Her current research examining profiles of school climate perceptions among Latinx youth is funded by the Spencer Foundation.

Dr. Stephen E. Brock is a Professor, and the School Psychology Program Coordinator, in the College of Education at California State University, Sacramento (CSUS). A Nationally Certified School Psychologist and Licensed Educational Psychologist, Dr. Brock worked for 18 years as a school psychologist with the Lodi (CA) Unified School District before joining the CSUS faculty. He is lead editor of the Best Practices in School Crisis Prevention and Intervention (2nd ed.), lead author of School Crisis Prevention and Intervention: The PREPaRE Model, and a lead author of the NASP PREPaRE Crisis Prevention and Intervention Curriculum. 